Bangladesh J. Sci. Res. 30(1\&2): 35-43, 2017 (December)

\title{
SILT CONTENT APPROXIMATION OF NEOGENE SURMA GROUP MUDROCKS, SITAKUND ANTICLINE, BENGAL BASIN
}

\author{
Md. Yousuf Gazi*, S.M. Mainul Kabir and Md. Badrul Imam \\ Department of Geology, University of Dhaka, Dhaka-1000, Bangladesh
}

\begin{abstract}
Petrography of the Neogene mudrocks in this study incorporates laser particle size analysis, thin sections and scanning electron microscopy (SEM). Ten representative mudrock samples were collected from outcrops of the Sitakund structure. From the studies, it is evident that mudrocks of Sitakund structure are characteristically silty. The silt content, as estimated by laser grain size analysis, of the mudrocks ranges from 39 to $77 \%$ with average of $58 \%$. Significant amount of granular silt with the platy clay minerals is also evident from the SEM micrographs. The silts are mainly quartz, feldspar and micas. The high silt content in the Neogene mudrocks implies an enormous flux of silty sediments with a very high rate of sedimentation allowing little time for a more selective sorting. This supports the geologic history that the uplifting and erosion of Himalaya was at the peak during Miocene and the Ganges mega delta received highest rate of sedimentation and growth rendering shale consistently silty.
\end{abstract}

Key words: Grittiness, Neogene Surma Group, Mudrocks, Bengal basin, SEM, Thin sections, Laser particle size analysis

\section{Introduction}

The Surma Group is the prime stratigraphic unit in Bangladesh with major economic and academic importance. Neogene shales of the Bengal basin comprises a major lithology of drilled along with outcropping sections. The Miocene-Pliocene Surma Group, the most important proliferous unit in Bangladesh due to the presence of reservoir quality sandstone and forming the mainstay of folded belt, is a clastic deltaic sequence with an average sandstone: shale ratio $1: 1$ although in many sections, shale outweighed and individual shale units are hundreds of meters thick (Alam et al. 2003). Admixture of sand and silt degrades the sealing properties of clays.

Not only the mineral composition of a rock and organic matter content, but also the grain size range are important in forming the major sealing properties of clays. Clay minerals lower permeability and improve sealing capabilities through the permanency in the composition of the silicate layer. With increasing grain size, permeability improves and degrades the seal potentiality. Detrital quartz, feldspar and micas in mudrocks have attained a great deal of study by sedimentary petrographers since the pioneering work of Sorby (1880).

Grain size, shape, internal structure, and geochemical characteristics have been inspected using a variety of tools ranging in complex to simple petrographic microscope. Silt in mudrocks, however, have received very little attention in spite of the fact that these rocks contain $30 \%$ more

*Author for correspondence: <yousuf.geo@du.ac.bd>. 
detrital quartz than do sandstones (Blatt and Schultz 1976). The cause for the negligence of quartz content and, indeed, of the entire non-clay mineral fraction of mudrocks can be outlined to the following two factors. Firstly, much of the quartz is of silt size, is hidden by clay minerals in thin section and is tremendously difficult to discriminate from untwined feldspar in silt sizes.

Secondly, disaggregation of mudrocks is time consuming and of unclear precision. The grittiness of Neogene Surma Group mudrocks were not documented and established before but it is very crucial to estimate the content of silt. There are several significances of this study in relation to sedimentology, petroleum geology and economic geology. The purposes of the present investigation are to determine the average amount of silt content in mudrocks from advanced laboratory techniques and average composition of silt portion.

Geologic settings: Bengal basin can be ascribed to the interaction of three plates; the Indian, Tibetan (Eurasian), and Burma (West Burma) plates. Burmese plate has moved toward the Indian plate beginning in the Miocene and superseded the Indian plate to form a subduction zone between the two plates. Convergence between India and Burma has resulted in subduction of oceanic crust beneath Burma, with the trailing margin of India currently passing obliquely into the foreland of the Indo-Burman ranges (Mukhopadhyay and Dasgupta 1988, Alam et al. 2003). The eastern fold belt represents the outermost part of the zone of compression between the west Burma block and the Indian plate.

The north-south-trending folds in this belt declines in amplitude and become broader and less complex westwards. Intensity of folding rapidly attenuates westwards; the central and western parts of the basin are relatively un-deformed. The age of folding ranges from the Pliocene to recent. During repeated transgressions and regressions, the Bhuban and Bokabil formations (Lower to Middle Miocene Surma Group) have been deposited. The group consists of dark grey shale, siltstone, fine to coarse grained sandstone, and occasional intraformational conglomerate, and gets a thickness of more than $4 \mathrm{~km}$ in the eastern fold belt. Bokabil formations shale dominated in the upper part unit, conventionally identified as the 'Upper Marine Shale', which signifies the last marine transgression over the Sylhet trough in north-eastern part of the Bengal basin (Holtrop and Keizer 1970).

The upper Mio-Pliocene Tipam Group is divided into the Tipam sandstone and Girujan clay formations. The Tipam sandstone typically comprises of yellowish brown to reddish brown, coarse grained, cross-bedded to ripple-laminated sandstone with minor silt stone and mudstone and interpreted as deposits of bed load-dominated low-sinuosity braided-fluvial systems (Johnson and Alam 1991). The Girujan clayis interpreted as lacustrine and fluvial over bank, composed of brown, blue and grey mottled clay, deposits (Reimann and Hiller 1993). The Dupi Tila sandstone is fining-upward sequences, with alternating channel-fill and floodplain deposits, have been interpreted as deposits of high-sinuosity meandering river systems (Johnson and Alam 1991). 




Fig. 1. Regional tectonic map showing major tectonic elements of the Bengal basin (after Uddin and Lundberg 1999).

\section{Materials and Methods}

Fourteen slides were imaged using a scanning electron microscopy (SEM) were performed using a JEOL/EO (version 1.0) to study the morphological nature of the clay. Scanning electron microscope with a back scattered electron detector and a standard view field of $150 \mu \mathrm{m}$ at $20 \mathrm{kV}$ accelerating voltage. SEM is done without sputtering and analysed on fracture surface. Sample was prepared by platinum coating.

In order to prepare a standard thin section of the collected samples, these were first cut by cutting machine to small chips. The chips were washed by water and acetone to remove gases or bubbles from the samples. The samples were rubbed on a glass plate until the surface becomes smoothed. The samples were then polished on a grinder and then on a glass plate by carborundum until smooth and flat surface was achieved. The polished surface was then cleaned with water and dried. The smooth flat surface of the sample was mounted on a clean microscope slide by araldite glue. This was done with care so that excess glue or air bubbles were removed from the slide. Then the free face of the sample was grinded on a grinding lap until light could pass through it. 
The thickness of the sample has been checked regularly using a polarizing microscope until the required thickness $(0.03 \mathrm{~mm})$ was achieved.

Malvern Mastersizer 3000 was used for grain size analysis. The samples used for LASER analysis were the representative of the bulk. The collected samples were hard and clay laminas was separated from interlaminated samples. They were disaggregated by using $6 \%$ conc. hydrogen per oxide with small amount of water in different sample beaker and kept them preserved for two days. Sometimes stirrer was used carefully to make them dispersant. Samples were decanted in sundry for two days.

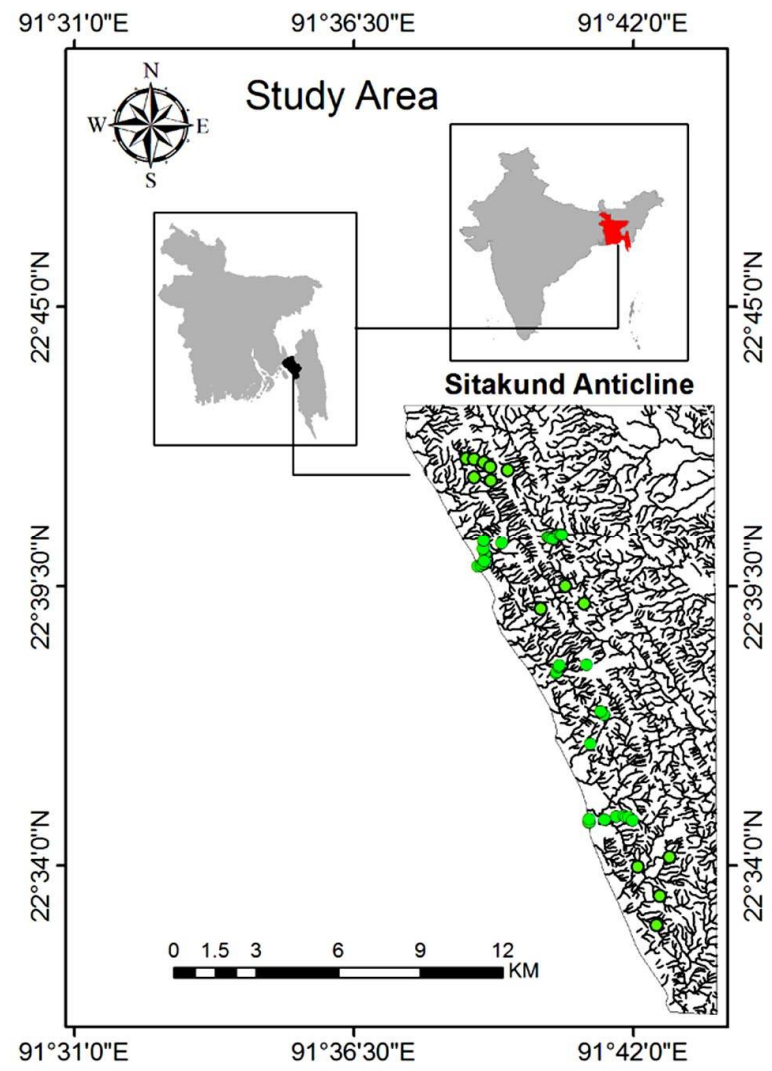

Fig. 2. Map showing the collected sample location from the study area.

They were sieved to achieve the standard of the instrument. Finally, they were LASER treated. For dispersants with high surface tension, such as deionized water was used; the addition of a small amount of surfactant significantly improved the wetting behaviour and subsequent particle dispersion. In order to disperse individual particles, energy applied to the sample. Often this is done through stirring or agitation, but for very fine materials or strongly bound agglomerates ultrasonic irradiation was sometime used. Samples were run through sonication to reduce bubble effect. 


\section{Results and Discussion}

In a Malvern Mastersizer result analysis report of Particle Size Analyser the D50 is represented as $\mathrm{D}(0.50)$. D represents the diameter of powder particles, and D50 means a cumulative $50 \%$ point of diameter (or 50\% pass particle size); D10 means a cumulative 10\% point of diameter; D50 is also called average particle size or median diameter; D $(4,3)$ means volume mean diameter, and $\mathrm{D}(3,2)$ means plane mean diameter.

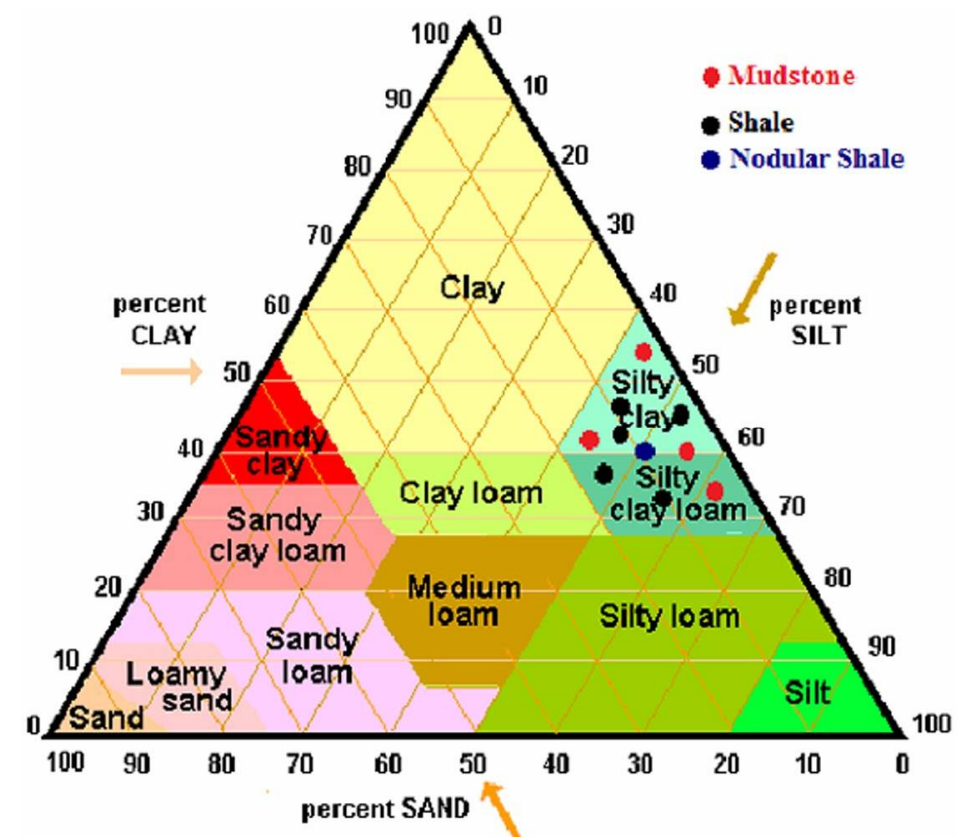

Fig. 3. Histogram and cumulative (Both oversize and undersize) curve from LASER particle analysis of some representative samples (From top, LC-1, BC-7 and BK-2).

The present contribution describes the application of a simple quantitative method of analysis of silt content in mudrocks using Laser particle size analysis. The data set comprises analyses from over 10 outcrop samples from Sitakund anticline. From Laser particle size analyzer, it is evident that over $60 \%$ particles are within the range of silt portion. Taking the average parcentage of silt and by plotting them in texutural ternary diagram shows that analyzed samples occupy the region zonned by silty clay and silty clay loam.

Darker tones in thin sections are mainly clay matrix and lighter tones are silty. In thin sections, the average ratio of clay to silt size dominated material is $42: 58$. The detrital grains of the coarse-grained zones are mainly quartz situated in a matrix of mixed mineral contents without mutual contact. Some samples are laminated with coarser and finer grained units and grains oriented sub-parallel with lamination. Upon sedimentation the detrital grains thus formed a lose network which was subsequently filled with cements. 



Fig. 4. Textural Ternary classification of studied samples (USDA Textural Classification Study Guide 1987).

Major mineral phase is quartz, plagioclase and potassium feldspar. Muscovite is mainly present in the fine-grained zones arranged with indistinct lamination. Chlorite and biotite is present in significant amount. Black/opaque hairy or fibres-like arranged organic material is present in fine grained zones. Muscovite grains (yellow interference colours) are present in fine grained unit. Grains with grey and white interference colours are mainly quartz in crossed polar. 



Fig. 5. Thin sections of some representative samples under cross polarized light with field view of $20 * / 0.40$ Pol. showing the richness of silty materials (from top left LC-1, BC-7, MC-5 and BK-2).

Table 1. Table showing the relative percentage of silt determined arbitrarily from thin section and laser particle size distribution.

\begin{tabular}{cccc}
\hline $\begin{array}{c}\text { Sample (from older to } \\
\text { younger) }\end{array}$ & $\begin{array}{c}\text { Approx. \% of silt } \\
\text { (quartz content) from } \\
\text { thin section }\end{array}$ & $\begin{array}{c}\text { Approx. \% of silt } \\
\text { (quartz content) from } \\
\text { Laser }\end{array}$ & Mean \\
\hline LC-1 & 35 & 43 & 39 \\
LC-4 & 45 & 50 & 47.5 \\
LC-10 & 50 & 55 & 52.5 \\
BC-7 & 55 & 65 & 60 \\
BC-10 & 60 & 68 & 64 \\
MC-5 & 60 & 70 & 65 \\
MC-7 & 65 & 73 & 69 \\
BK-4 & 75 & 75 & 75 \\
BK-2 & 75 & 79 & 77 \\
\hline
\end{tabular}


Scanning electron micrograph illustrating the domains of randomly oriented clay minerals in a silt-rich shale interval of the Sitakund anticline. Image showing some detrital and authigenic quartz grains, including compositional zoning of trace elements or overgrowths. Samples are dominated by quartz and kaolinite. Quartz grains are mostly crystalline. Minor amount of potash feldspar is evident. Fibrous illite occurs as laths in between the quartz and kaolinite. Kaolinites are flat disc shape. Some authigenic pyrites are distinct as small cluster of spotted body on the crystal face of quartz and kaolinite minerals. Presence of chaotic structures in clay minerals and quartz coating detrital sediments are indicating detrital origin of minerals.
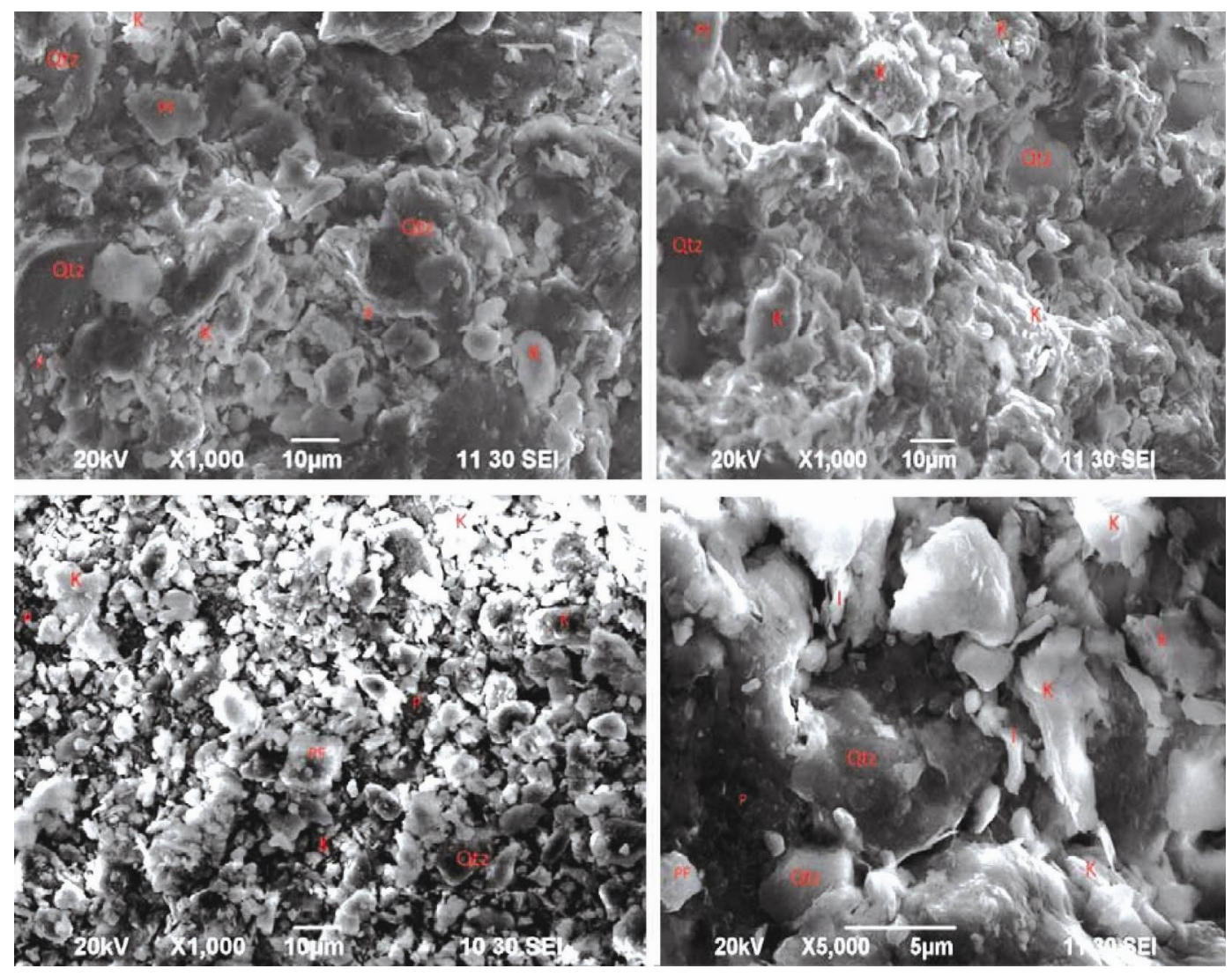

Fig. 6. Scanning electron micrograph of some representative samples showing the coarse grains and clay booklets adjacent to silt grain boundary (From top left LC-1, BC-7, MC5 and BK-2).

\section{Conclusion}

The employed laboratory techniques suggest that Surma group mudrocks are silt dominated. The silt content, as projected from the analyses, of the mudrocks fluctuate from 39 to $77 \%$ (av. 58\%). Quartz, feldspar and micas are major minerals contributing the silt portion of the mudrocks. SEM and thin sections also justify the presence of silt richness. 
The silt enrichment of the Neogene Surma group mudrocks testify the huge influx of detrital grain of quartz to the mud depositional system. Due to the presence of this grittiness, Neogene Surma group mudrocks cannot be defined as pure seal for petroleum entrapment. The mudrocks will play as leaky seal for their gritty nature.

\section{Acknowledgements}

The authors would like to thank Dr. Mohammod Nadim Zaman (Institute of Mining, Mineralogy and Metallurgy, BCSIR, Joypurhat) for his kind permission to use petrography laboratory. They deeply acknowledge the authority of Centre for Advanced Research in Sciences (CARS), University of Dhaka and USAID PEER Science Grant for giving them the opportunity to use SEM and Laser Particle Size Analyser.

\section{References}

Alam, M., M.M. Alam, J.R. Curray, M.L.R. Chowdhury and M.R. Gani. 2003. An overview of the sedimentary geology of the Bengal Basin in relation to the regional tectonic framework and basin-fill history: Sedimentary Geology 155: 179-208.

Blatt, H. and D.J. Schultz. 1976. Size distribution of quartz in mudrocks. Sedimentology 23(6): 857-866.

Holtrop, J. F. and J. Keizer. 1970. Some aspects of the stratigraphy and correlation of the Surma Basin wells, East Pakistan. ECAFE Mineral Resources Development Series 36: 143-154.

Johnson, S.Y. and A.M.N. Alam.1991. Sedimentation and tectonics of the Sylhet trough, Bangladesh. Geological Society of America Bulletin 103(11): 1513-1527.

Mukhopadhyay, M. and S. Dasgupta. 1988. Deep structure and tectonics of the Burmese arc: constraints from earthquake and gravity data. Tectonophysics 149(3-4): 299-322.

Reimann, K. U. and K., Hiller. 1993. Geology of Bangladesh.

Sorby, H. 1880. On the structure and origin of non-calcareous stratified rocks: Quart. Jour. Geol. Soc. London 36: 43-54.

Uddin, A. and N., Lundberg. 1999. A paleo-Brahmaputra? Subsurface lithofacies analysis of Miocene deltaic sediments in the Himalayan-Bengal system, Bangladesh. Sedimentary Geology 123(3-4): 239-254.

USDA Textural Soil Classification Study Guide 1987. Soil Mechanics Level I. Module 3.

(Manuscript received on 12 July, 2017; revised on 12 February, 2018) 